\title{
Sumoylation in gene regulation, human disease, and therapeutic action
}

\author{
Xiang-Jiao Yang ${ }^{1,2 *}$ and Cheng-Ming Chiang ${ }^{3-5 *}$
}

\author{
Addresses: ${ }^{1}$ The Rosalind \& Morris Goodman Cancer Research Center, McGill University, Montréal, Québec, H3A 1A3, Canada; \\ ${ }^{2}$ Department of Medicine, McGill University, Montréal, Québec, H3A 1A3, Canada; ${ }^{3}$ Simmons Comprehensive Cancer Center, University of \\ Texas Southwestern Medical Center, Dallas, TX 75390-8807, USA; ${ }^{4}$ Department of Biochemistry, University of Texas Southwestern Medical Center, \\ Dallas, TX 75390-8807, USA; ${ }^{5}$ Department of Pharmacology, University of Texas Southwestern Medical Center, Dallas, TX 75390-8807, USA \\ *Corresponding authors: Xiang-Jiao Yang (xiang-jiao.yang@mcgill.ca) and Cheng-Ming Chiang (cheng-ming.chiang@utsouthwestern.edu) \\ FI000Prime Reports 2013, 5:45 (doi:10.12703/P5-45) \\ This is an open-access article distributed under the terms of the Creative Commons Attribution-Non Commercial License \\ (http://creativecommons.org/licenses/by-nc/3.0/legalcode), which permits unrestricted use, distribution, and reproduction in any medium, \\ provided the original work is properly cited. You may not use this work for commercial purposes. \\ The electronic version of this article is the complete one and can be found at: http://fl 000.com/prime/reports/b/5/45
}

\begin{abstract}
Similar to ubiquitination, sumoylation covalently attaches a small ubiquitin-like modifier (SUMO) protein (92-97 amino acids) to the $\varepsilon$-amino group of a lysine residue. This is quite different from the classically defined post-translational modifications, such as phosphorylation, acetylation, and methylation, which typically add a small chemical group to the targeted residue. Sumoylation has been well studied at the molecular and cellular levels, focusing mostly on site-specific conjugation of human SUMOI, SUMO2, and SUMO3, as well as their homologues in various species. In this short review, we will discuss some recent examples to highlight (a) emerging trends about the coordinated regulation of sumoylation and other post-translational modifications in modulating the function of some transcription factors and pathway-specific regulators, (b) diverse roles of sumoylation in gene regulation implicated in stem cells and different pathogenic conditions, and (c) potential therapeutic strategies related to some of the diseases stated above.
\end{abstract}

\section{Introduction}

First reported by two research groups in late 1996 and early $1997[1,2]$, sumoylation is now known to modify various eukaryotic proteins in organisms ranging from yeast to humans. A recent proteomic analysis of sumoylated proteins identified over 580 endogenous targets in human cervical carcinoma-derived HeLa cells, corresponding to approximately $2 \%$ of the entire proteome [3]. This modification adds an approximately $10 \mathrm{kDa}$ small ubiquitin-like modifier (SUMO) polypeptide to the $\varepsilon$-amino group of certain lysine residues. SUMO polypeptides are approximately $18 \%$ identical to ubiquitin at the amino acid sequence level and their three-dimensional (3D) structural folds are highly similar to that of ubiquitin [4-6]. Like ubiquitination, sumoylation is governed by a conserved cascade consisting of a heterodimeric E1-activating enzyme complex, an E2-conjugating enzyme, and an E3 ligase [4,7]. While there is only one E1 or E2 enzyme, multiple E3 ligases have been identified. The conjugated SUMO moieties are synthesized as precursors, which are cleaved by Sentrin/SUMO-specific proteases ([SENPs] up to seven in humans) to expose the C-terminal diglycine required for covalent attachment to target proteins [8]. In addition, SENPs control desumoylation, rendering the modification dynamic and reversible [9].

Both ubiquitination and sumoylation attach small proteins to targets, and these small proteins serve as platforms for interaction with other proteins. This is quite different from other post-translational modifications (PTMs), such as phosphorylation, acetylation, and methylation, which add small chemical groups and thus use mechanisms distinct from ubiquitination and sumoylation to exert their functional impacts. Another aspect of difference is that attached ubiquitin and SUMO moieties form domains for recognizing short peptide motifs on binding partners, whereas phosphorylation, acetylation, and methylation are recognized by modification-specific 
protein domains [10]. Short motifs recognized by SUMO polypeptides are known as SUMO-interaction motifs, which conform to a well-conserved consensus sequence and can thus be used to predict and identify SUMO interaction sites on binding partners [4-6].

Sumoylation has been well studied at the molecular and cellular levels (for reviews, see $[4,5,7,11,12]$ ). In what follows, we will describe some recent examples to highlight emerging trends about the coordinated regulation of transcription factors and other proteins by sumoylation and to discuss the diverse roles of this PTM in gene regulation, stem cell biology, and human diseases. Particular attention is given to related studies that have been published over the past four to five years. For this, we will start with a brief description about the classification of different sumoylation sites.

\section{Different types of sumoylation motifs}

Classical sumoylation sites conform to the consensus sequence $\psi \mathrm{KxE}$, where $\psi$ is a bulky hydrophobic amino acid (such as I, $\mathrm{L}$, and V) and $\mathrm{x}$ can be any residue (Figure 1 ) $[6,7,13,14]$. A subgroup of known sumoylation sites contains one or a few acidic residues located two or three residues downstream from the core motif $\psi \mathrm{KxE}$ to form a negatively charged amino acid-dependent sumoylation motif (NDSM) (Figure 1) [15]. The negative charge enhances the binding affinity for the E2-conjugating enzyme Ubc9 (ubiquitin carrier protein 9) that contains a positively charged $\psi$ KxE-binding pocket (Figure 2a) $[15,16]$. Similar to the negatively charged motif is the phosphorylation-dependent sumoylation motif (PDSM), $\psi \operatorname{KxExxS} / \mathrm{T}$ (Figure 1), conserved among a number of transcription factors, including HSF1 (heat shock factor 1), PPAR $\gamma$ (peroxisome proliferator-activated receptor $\gamma$ ), MEF2 (myocyte enhancer factor 2), and estrogen-related receptors (ERRs) [17-20]. Signal-dependent phosphorylation of the serine or threonine residues promotes sumoylation in response to different signaling cues [21]. A third subgroup of classical sumoylation motifs possesses an N-terminal cluster of hydrophobic residues to enhance sumoylation. Such motifs are known as hydrophobic cluster-containing sumoylation motifs (HCSMs) (Figure 1) [22]. A recent study further reveals an inverted sumoylation motif (iSM), E/DxK $\psi$ (Figure 1) [22]. These classical and inverted consensus sequences help predict new sumoylation sites, especially when the putative sites are located at evolutionarily conserved sequence islands. Sumoylation is quite different from ubiquitination and other PTMs, such as acetylation and methylation, for which the surrounding sequences have a rather limited value in predicting the modification sites. It should be noted, however, that according to a proteomic analysis, atypical sites with little sequence similarity to the above motifs are also important
Figure I. Different types of sumoylation consensus sequences

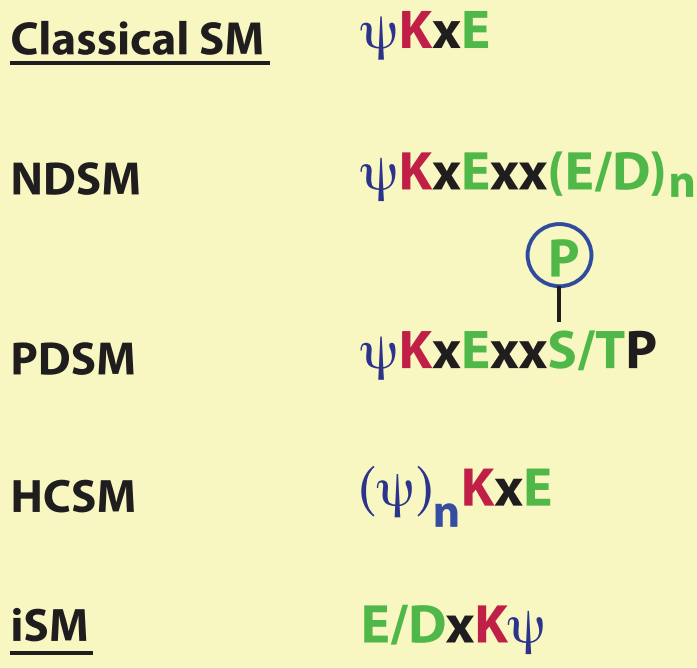

Sumoylation motifs (SMs) are grouped into two major categories: classical and inverted. Within the classical category, two subgroups contain downstream acidic clusters or phosphorylatable serine/threonine residues to form extended SMs known as negatively charged amino acid-dependent small ubiquitin-like modifier (SUMO)-conjugation motifs (NDSMs) and phosphorylation-dependent sumoylation motifs (PDSMs), respectively. For NDSMs, the spacing between the SM and the acidic patch could be either two or three residues. In addition, a third subgroup possesses an $\mathrm{N}$-terminal cluster of hydrophobic residues, known as hydrophobic cluster-containing sumoylation motifs (HCSMs). It is unclear whether these three types of extended motifs exist within the category of inverted sumoylation motifs (iSMs). $\psi$, bulky hydrophobic residues, such as $\mathrm{I}, \mathrm{L}$ or $\mathrm{V} ; \mathrm{x}$, any residue; $\mathrm{n}$, two or more (although, even one acidic residue also promotes sumoylation).

for sumoylation [14]; in such cases, the motifs are of no predicting value.

\section{Selective regulation of NDSM sumoylation by Ubc9 acetylation}

The E2 SUMO-conjugating enzyme Ubc9 is itself subject to regulation by PTMs. A recent study reveals that Ubc9 is acetylated at Lys-65 and the acetylation selectively reduces the sumoylation of NDSM-containing proteins, such as the ETS-domain transcription factor ELK1 (Figure 2a and b) and the acetyltransferase transcriptional coactivator CBP [23]. The acidic patch within an NDSM (Figure 1) forms a negatively charged surface for interaction with a positively charged cluster formed by Lys-65, Lys-74, and Lys-76 of Ubc9 (Figure 2a) [16]. These three residues are in proximity on the 3D structure [16]. By disrupting this charge interaction, Lys-65 acetylation decreases NDSM sumoylation of proteins such as ELK1 (Figure 2b) and CBP but has 
Figure 2. Mechanisms by which Ubc9 recognizes the extended sumoylation motifs

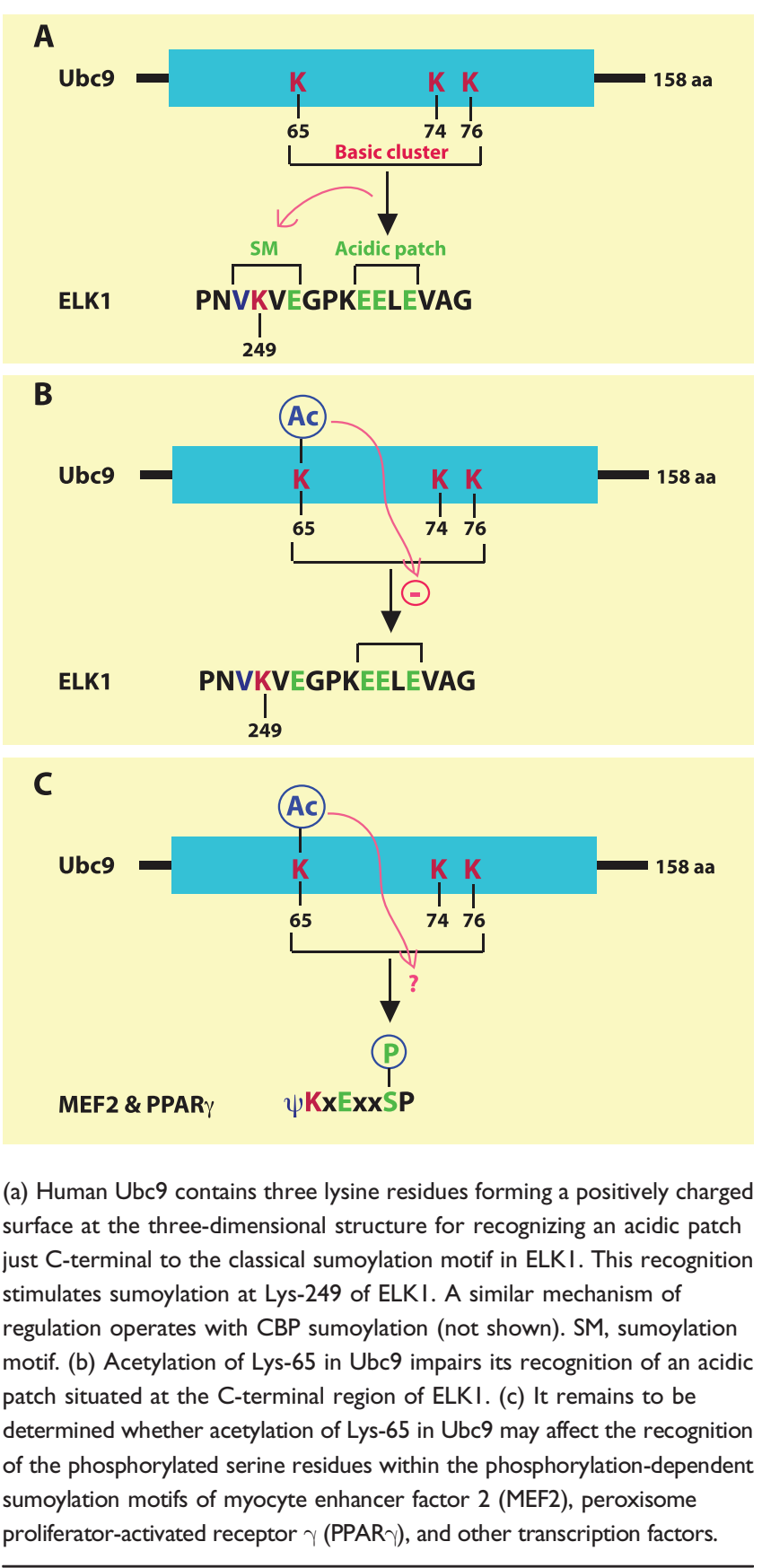

no impact on the sumoylation of Daxx and TCF4, which contain regular motifs without an acidic patch [23]. PDSMs also utilize the positively charged cluster of Ubc9 for phosphorylation-dependent sumoylation [21], so it remains an interesting question whether Lys-65 acetylation of Ubc9 inhibits the sumoylation of PDSMs in transcription factors, such as the MADS-box transcription factor MEF2 and the nuclear receptor PPAR $\gamma$ (Figure 2c).
Besides acetylation, Ubc9 itself is also sumoylated, which serves as a cofactor to promote efficient SUMO transfer and stimulate polysumoylation of target proteins [24]. It will likewise be interesting to know whether other modifications, such as phosphorylation and ubiquitination, modify Ubc9 and regulate its enzymatic activity. ELK1 sumoylation is inhibited by its own phosphorylation by MAP kinases [25], so it is important to determine how this regulation coordinates with Ubc9 acetylation.

\section{Crosstalk of sumoylation with other modifications for coordinated regulation}

As described above for PDSMs (Figure 1), sumoylation is often regulated by other PTMs occurring at regions flanking the sumoylated site. The crosstalk between sumoylation and other PTMs is well exemplified by the tumor suppressor p53, whose last 30 amino acids ([aa] 363-393 of human p53) are heavily modified by sumoylation, ubiquitination, neddylation, phosphorylation, acetylation, and methylation (Figure 3a) [26-28]. A single sumoylation site identified at Lys-386 of human p53 represents an SM similar to NDSMs and PDSMs (Figure 3a), in that Ser-392 is flanked by two Asp residues (that is, DSD) and becomes acidic upon phosphorylation by cellular kinases, such as

Figure 3. Crosstalk among post-translational modifications at the $\mathrm{p} 53 \mathrm{C}$-terminal regulatory region

A

p53 CRD (aa 363-393)
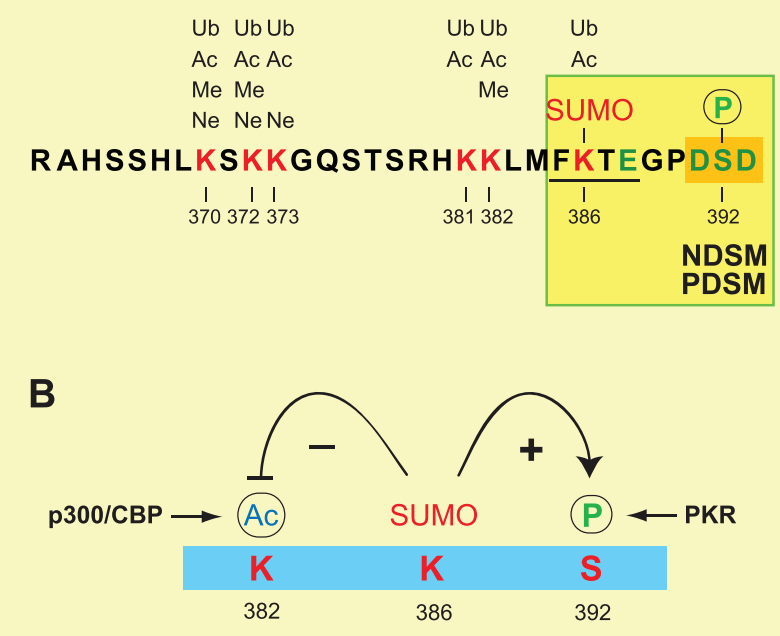

(a) The last 30 amino acids in human p53 (aa 363-393) showing the sites specifically modified by ubiquitination (Ub), acetylation (Ac), methylation $(\mathrm{Me})$, neddylation ( $\mathrm{Ne}$ ), sumoylation (SUMO), and phosphorylation $(\mathrm{P})$. (b) Sumoylation of $\mathrm{p} 53$ at Lys-386 enhances Ser-392 phosphorylation by PKR but inhibits Lys-382 acetylation by $\mathrm{P} 300 / \mathrm{CBP}$. 
CDK9, CK2, and PKR [29,30]. Although it remains unclear whether Ser-392 phosphorylation stimulates Lys-386 sumoylation, as shown for other PDSMs, this sumoylation is known to enhance Ser-392 phosphorylation by PKR (Figure 3b) [30]. In contrast, sumoylation of Lys-386 inhibits Lys-382 acetylation by p300/CBP, presumably due to steric hindrance of the SUMO moiety preventing p300/ $\mathrm{CBP}$ access to the adjacent lysine residue (Figure 3b) [31]. Additional examples of crosstalk among PTMs include sumoylation-dependent ubiquitination of PML (promyelocytic leukemia protein) [32,33]; sequential phosphorylation, sumoylation, and ubiquitination in governing the fate of FEN1 (flap structure-specific endonuclease 1) during cell cycle progression [34]; coordinated redox-dependent sumoylation and acetylation in regulating the activity of HIPK2 (homeodomain-interacting protein kinase 2) in response to oxidative stress [35]; and phosphorylationdependent sumoylation of the phosphatase PTEN (phosphatase and tensin homolog) [36,37]. Clearly, PTMs occurring at the flanking regions of a SUMO-conjugation site dictate the efficiency of sumoylation and its functional outcomes.

\section{Impact of sumoylation on cancer and other diseases}

The basic helix-loop-helix leucine zipper (bHLH-LZ) transcription factor MITF (microphthalmia-associated transcription factor) plays an important role in melanocyte and osteoclast development [38]. Loss-of-function mutations have been linked to microphthalmia, a developmental disorder that causes small eyes [38]. MITF possesses two classical sumoylation motifs, Lys-182 and Lys-316, flanking its DNA-binding domain, with the latter being the major sumoylation site (Figure 4) $[39,40]$. Lys-316 is conserved in another family member, TFEB, which functions as a master regulator of lysosomal biogenesis [40]. Two recent studies have identified a recurrent heterozygous mutation in the MITF gene leading to the substitution E318K and predisposing fair-skinned individuals to familial and sporadic melanoma (Figure 4) $[41,42]$. This mutation is also associated with renal cell carcinoma [42]. Interestingly, the functional impact of this mutation is different from the total loss of MITF due to microphthalmia-causing mutations, which have no known links to cancer. As E318 is a crucial residue of the sumoylation motif (Figures 1 and 4), the E318K substitution inhibits MITF sumoylation and affects transcription of its target genes. In support of a causal role in oncogenesis, this mutant promotes migration, invasion, and clonogenicity of melanoma and renal cancer cells. In addition, two more recent studies identified the same mutation in melanoma patients from Italy and Queensland $[43,44]$. Thus, the loss of MITF sumoylation is positively linked to oncogenesis.

In contrast, sumoylation is required for Myc-dependent tumorigenesis. Both MITF and Myc are bHLH-LZ transcription factors. A genome-wide RNA interference (RNAi) screen identified the heteromeric SUMO-activating enzyme complex, SAE1/2 (SUMO-1-activating enzyme subunits 1 and 2), as a synthetic lethal gene product with Myc [45]. Inactivation of SAE2, expected to disable the sumoylation machinery, leads to mitotic catastrophe and cell death upon Myc hyperactivation. SAE2 inhibition activates a repressed transcriptional subprogram, although the underlying mechanism for this switch remains to be elucidated. Unlike MITF sumoylation, SUMO conjugation is required for Mycdependent tumorigenesis. Therefore, sumoylation of two transcription factors with similar DNA-binding domains exerts completely opposite effects on cancer development. Along with the aforementioned roles of sumoylation in regulating the functions of the tumor suppressors p53, PTEN, and PML, it is clear that this modification is intimately linked to tumor initiation and progression.

Figure 4. Deregulation of microphthalmia-associated transcription factor (MITF) sumoylation is associated with predisposition to melanoma and renal cell carcinoma

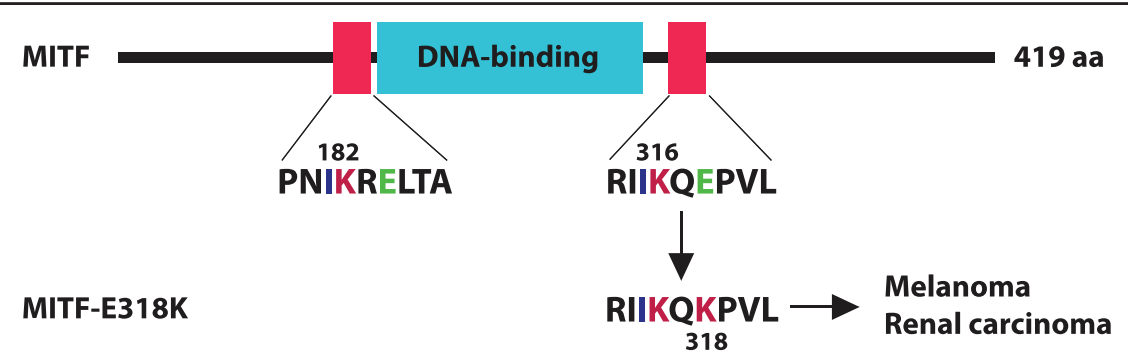

MITF possesses two sumoylation sites, Lys- 182 and Lys-316, flanking the DNA-binding domain, Lys- 182 and Lys-316, with the latter being the major one. The E318K substitution impairs Lys-316 sumoylation and leads to increased risk of melanoma and renal carcinoma. aa, amino acids. 
Sumoylation has been linked to human diseases other than cancer. First, impaired calcium uptake due to decreased expression and reduced activity of the calcium-transporting ATPase SERCA2a are hallmarks of heart failure [46]. SERCA2a is sumoylated at two classical sumoylation motifs and their modification correlates with beneficial health effects [46]. Second, infection by Listeria monocytogenes, a facultative intracellular pathogen responsible for human listeriosis, induces degradation of Ubc9, leading to subsequent decreases in the sumoylation of cellular proteins [47]. Enhanced activity of the sumoylation machinery is thus linked to reduced infection. Third, various viruses harness the sumoylation machinery to modulate virus-host interaction [48]. Finally, as discussed in the next section, sumoylation of the nuclear receptor PPAR $\gamma$ modulates adipocyte differentiation and the development of diabetes.

\section{PPAR $\gamma$ sumoylation in antidiabetic therapy}

PPAR $\gamma$ is a ligand-activated transcription factor highly expressed in white fat tissue. Like other nuclear receptors, PPAR $\gamma$ contains a DNA-binding domain and a ligandbinding domain (Figure 5) [49]. A major sumoylation site, Lys-107 of PPAR $\gamma 2$ (corresponding to Lys-77 in the $\gamma 1$ isoform), is located at the N-terminal transcriptional activation domain, and another site, Lys-395, is situated in the ligand-binding domain [50]. Downstream from Lys107 is an SP motif, which is subject to phosphorylation and is important for sumoylation at Lys-107 (Figure 5). Lys-107 and Ser-112 thus form a typical PDSM (Figure 1) [51], in which Lys-107 sumoylation inhibits PPAR $\gamma$ activity [51-53].

PPAR $\gamma$ regulates the expression of many target genes, including the one coding for fibroblast growth factor- 21
(FGF21) [49]. To activate the signaling, the circulating hepatokine binds to a heteromeric tyrosine kinase complex composed of $\beta$-Klotho and an FGF receptor (FGFR). When administered to obese, insulin-resistant rodents and monkeys, FGF21 beneficially affects carbohydrate and lipid metabolisms by inducing energy expenditure, insulin sensitivity, and weight loss [49]. A recent study of FGF21-knockout mice reveals that this hepatokine inhibits PPAR $\gamma$ sumoylation at Lys-107 and triggers feed-forward regulation [54]. This modification regulates the size of adipocytes. The antidiabetic drug rosiglitazone, a PPAR $\gamma$ agonist, decreases sumoylation and enhances insulin sensitivity. Therefore, inhibition of PPAR $\gamma$ sumoylation exerts beneficial health effects. However, this inhibition also correlates with the side effects of PPAR $\gamma$ agonists in treating type 2 diabetes.

\section{Sumoylation in pluripotent and intestinal stem cells: insights from studies of Ubc9-null mice}

As mentioned in the Introduction section, the sumoylation pathway involves the sole E2-conjugating enzyme Ubc9, which provides a unique opportunity for genetic analysis of sumoylation functions in vivo. A complete disruption of the mouse Ubc9 gene leads to early embryonic lethality, even though the heterozygous mice are fertile and display no overt phenotypes [55]. Although removal of one allele does not affect sumoylation levels, inactivation of both alleles is expected to block sumoylation. $U b c 9^{-/-}$blastocysts recovered at E3.5 appear normal under a light microscope, but the inner cell mass, which contains the endogenous pluripotent embryonic stem cells, fails to expand and displays apoptosis [55], indicating that Ubc9 is required for the survival of the pluripotent stem cell population during early development of mouse embryos. Moreover, nuclear

Figure 5. Regulation of peroxisome proliferator-activated receptor $\gamma($ PPAR $\gamma$ ) sumoylation by cellular signaling

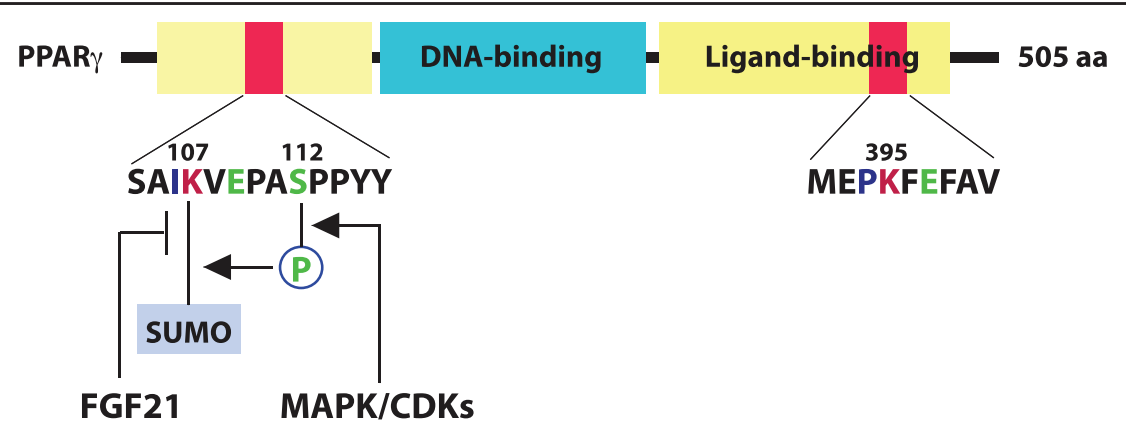

PPAR $\gamma 2$ possesses two sumoylation sites, Lys- 107 and Lys-395 (corresponding, respectively, to Lys-77 and Lys-365 of the shorter $\gamma 1$ isoform). While Lys-395 sumoylation is ligand-dependent in macrophages, Ser II 2 phosphorylation promotes sumoylation of Lys- 107. In contrast, fibroblast growth factor-2I (FGF2 I) antagonizes Lys- 107 sumoylation, although the underlying mechanism has not been defined. aa, amino acids. 
organization and chromosomal segregation are abnormal in cells from E3.5 mutant blastocysts [55]. Consistent with this observation, a dominant-negative inhibition of Ubc9 expression in zebrafish leads to embryonic cell death [56].

In light of this early embryonic lethality, a LoxP-based conditional mouse line $\left(U b c 9^{\mathrm{f} /+}\right)$ was engineered to study tissue-specific and postnatal functions of mouse Ubc9 [57]. Crosses between this and the above $U b c 9^{+/-}$mice yielded a heterozygous line, $U b c 9^{\mathrm{f} /}$. . Further mating with the ROSA26-CreERT2 strain, in which expression of the CreERT2 fusion protein is under the control of the ubiquitous ROSA26 promoter, enables a tamoxifeninducible global deletion of the remaining copy of the Ubc9 gene [57]. Tamoxifen administration to 2- to 3-month-old mice led to severe diarrhea on the second day and subsequent death due to the intestinal failure within 6 days [57]. Analysis of different cells in the intestines revealed that Ubc9 is required in regions with active cell division, and deletion of the Ubc9 gene leads to rapid depletion of stem cells. Although this study indicates that Ubc9 is important for adult intestinal stem cells, the acute lethality prevents further analysis of its function in other tissues and organs. Further studies via tissue-specific deletion should help address this issue. Of relevance, antisense-based Ubc9 silencing in zebrafish reveals an important role for sumoylation in chondrocyte development, as well as in the specification and patterning of cranial neural crest and pharyngeal pouch cells [56].

In addition to playing an important role in embryonic stem cells and adult intestinal stem cells, sumoylation also regulates the activity of key transcription factors in induced pluripotent stem (iPS) cells. Ectopic expression of four reprogramming factors, Oct4 (also known as Pou5f1), Sox2 $\{[$ SRY (sex determining region Y)-box 2]\}, KLF4 (Krüppel-like factor 4), and c-Myc, leads to iPS cell formation [58]. Among these factors [58], Oct4, Sox2, and KLF4 are known to be sumoylated [59-62]. Sumoylation of these transcription factors negatively regulates reprogramming [63]. Similarly, sumoylation of the nuclear receptor NR5A inhibits reprogramming [64]. Moreover, ERRs (estrogen-related receptors) are subject to phosphorylation-dependent sumoylation and play a role in reprogramming $[20,65]$. The sumoylation inhibits their transcriptional activity [20] and is thus likely to inhibit reprogramming. The negative role of sumoylation in iPS cells is counterintuitive to the positive role of Ubc9 in embryonic stem cells and adult intestinal stem cells, suggesting that sumoylation of additional factors plays a positive role in the stem cells. Because of the enormous potential of stem cell therapy, further studies of Ubc9 and the sumoylation pathway in pluripotent and adult stem cells will provide novel insights for improved therapeutic strategies.

\section{Conclusions}

Since its discovery approximately 16 years ago $[1,2]$, sumoylation has emerged as a major post-translational modification for the regulation of transcription factors and other eukaryotic proteins. An emerging trend is that this modification does not act alone but interplays actively with other modifications, such as phosphorylation, acetylation, and ubiquitination, to form integrated modification programs for coordinated regulation of various proteins in response to diverse signaling cues. Different from many other modifications, many sumoylation sites are frequently located within conserved consensus sequences, which greatly facilitate the prediction of uncharacterized sumoylation sites (Figure 1) [6]. Recent studies provide a biological link from the sumoylation machinery to different human diseases, including melanoma, renal carcinoma, heart failure and diabetes, and pathogenic infection by bacteria and viruses. This modification is of relevance to therapeutic actions, as some antidiabetic drugs act directly on PPAR $\gamma$ sumoylation (Figure 5) [49]. Sumoylation is also important in different stem cells $[55,57,63]$ and is highly related to stem cellbased therapy. Therefore, by providing a regulatory switch in modulating protein functions, sumoylation has emerged as a promising target for the development of therapeutics against various human diseases.

\section{Abbreviations}

3D, three-dimensional; FGF, fibroblast growth factor; iPS, induced pluripotent stem; KLF4, Krüppel-like factor 4; MEF2, myocyte enhancer factor 2; MITF, microphthalmia-associated transcription factor; NDSM, negatively charged amino acid-dependent sumoylation motif; PDSM, phosphorylation-dependent sumoylation motif; PML, promyelocytic leukemia protein; PPAR $\gamma$, peroxisome proliferator-activated receptor $\gamma$; PTEN, phosphatase and tensin homolog; PTM, post-translational modification; SAE, SUMO-1-activating enzyme subunit; SENP, Sentrin/SUMO-specific protease; SM, sumoylation motif; Sox2, SRY (sex determining region Y)-box 2; SUMO, small ubiquitin-like modifier.

\section{Disclosures}

The authors declare that they have no competing interests.

\section{Acknowledgments}

Our work was supported by research grants from the Canadian funding agencies NSERC, CIHR, and CFI (to 
X-JY) as well as by US National Institutes of Health RO1 grant CA103867, CPRIT grants RP110471 and RP120340, and Welch Foundation grant I-1805 (to C-MC).

\section{References}

I. Matunis MJ, Coutavas E, Blobel G: A novel ubiquitin-like modification modulates the partitioning of the Ran-GTPase-activating protein RanGAPI between the cytosol and the nuclear pore complex. J Cell Biol 1996, I35: 1457-70.

\section{FlOOOPrime}

\section{RECOMMENDED}

2. Mahajan R, Delphin C, Guan T, Gerace L, Melchior F: A small ubiquitin-related polypeptide involved in targeting RanGAPI to nuclear pore complex protein RanBP2. Cell 1997, 88:97-I07.

\section{FlOOOPrime}

\section{RECOMMENDED}

3. Becker J, Barysch SV, Karaca S, Dittner C, Hsiao H, Berriel Diaz M, Herzig S, Urlaub H, Melchior F: Detecting endogenous SUMO targets in mammalian cells and tissues. Nat Struct Mol Biol 20I3, 20:525-3I.

\section{FlOOOPrime \\ RECOMMENDED}

4. Geiss-Friedlander R, Melchior F: Concepts in sumoylation: a decade on. Nat Rev Mol Cell Biol 2007, 8:947-56.

5. Hochstrasser M: Origin and function of ubiquitin-like proteins. Nature 2009, 458:422-9.

6. Gareau JR, Lima CD: The SUMO pathway: emerging mechanisms that shape specificity, conjugation and recognition. Nat Rev Mol Cell Biol 2010, I I:861-71.

7. Gill G: SUMO and ubiquitin in the nucleus: different functions, similar mechanisms? Genes Dev 2004, 18:2046-59.

8. Hay RT: SUMO-specific proteases: a twist in the tail. Trends Cell Biol 2007, I 7:370-6.

9. Yeh ETH: SUMOylation and De-SUMOylation: wrestling with life's processes. J Biol Chem 2009, 284:8223-7.

10. Yang $X$ : Multisite protein modification and intramolecular signaling. Oncogene 2005, 24:1653-62.

II. Müller S, Hoege C, Pyrowolakis G, Jentsch S: SUMO, ubiquitin's mysterious cousin. Nat Rev Mol Cell Biol 200I, 2:202-10.

12. Seeler J, Dejean A: Nuclear and unclear functions of SUMO. Nat Rev Mol Cell Biol 2003, 4:690-9.

13. Hay RT: SUMO: a history of modification. Mol Cell 2005, I8:I-I2.

14. Blomster HA, Hietakangas V, Wu J, Kouvonen P, Hautaniemi S, Sistonen L: Novel proteomics strategy brings insight into the prevalence of SUMO-2 target sites. Mol Cell Proteomics 2009, 8:1382-90.

15. Yang S, Galanis A, Witty J, Sharrocks AD: An extended consensus motif enhances the specificity of substrate modification by SUMO. EMBO J 2006, 25:5083-93.

16. Mohideen F, Capili AD, Bilimoria PM, Yamada T, Bonni A, Lima CD: A molecular basis for phosphorylation-dependent SUMO conjugation by the E2 UBC9. Nat Struct Mol Biol 2009, 16:945-52.

\section{FlOOOPrime} RECOMMENDED

17. Hietakangas $V$, Anckar J, Blomster HA, Fujimoto M, Palvimo J], Nakai A, Sistonen L: PDSM, a motif for phosphorylationdependent SUMO modification. Proc Natl Acad Sci USA 2006, 103:45-50.

18. Shalizi A, Gaudillière B, Yuan Z, Stegmüller J, Shirogane T, Ge Q, Tan Y, Schulman B, Harper JW, Bonni A: A calcium-regulated MEF2 sumoylation switch controls postsynaptic differentiation. Science 2006, 31 I:1012-7.

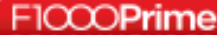

19. Grégoire S, Tremblay AM, Xiao L, Yang Q, Ma K, Nie J, Mao Z, Wu Z, Giguère V, Yang X: Control of MEF2 transcriptional activity by coordinated phosphorylation and sumoylation. I Biol Chem 2006, 28 I:4423-33.

20. Tremblay AM, Wilson BJ, Yang $X$, Giguère V: Phosphorylationdependent sumoylation regulates estrogen-related receptoralpha and -gamma transcriptional activity through a synergy control motif. Mol Endocrinol 2008, 22:570-84.

21. Yang X, Grégoire S: A recurrent phospho-sumoyl switch in transcriptional repression and beyond. Mol Cell 2006, 23:779-86.

22. Matic I, Schimmel J, Hendriks IA, van Santen MA, van de Rijke F, van Dam H, Gnad F, Mann M, Vertegaal ACO: Site-specific identification of SUMO-2 targets in cells reveals an inverted SUMOylation motif and a hydrophobic cluster SUMOylation motif. Mol Cell 2010, 39:64I-52.

23. Hsieh $Y$, Kuo H, Chang C, Naik MT, Liao P, Ho C, Huang T, Jeng J, Hsu P, Tsai M, Huang T, Shih H: Ubc9 acetylation modulates distinct SUMO target modification and hypoxia response. EMBO J 2013, 32:79I-804.

\section{FIOOOPrime}

\section{RECOMMENDED}

24. Klug $\mathrm{H}$, Xaver M, Chaugule VK, Koidl S, Mittler G, Klein F, Pichler A: Ubc9 sumoylation controls SUMO chain formation and meiotic synapsis in Saccharomyces cerevisiae. Mol Cell 20I3, 50:625-36.

25. Li Q, Yang S, Maeda Y, Sladek FM, Sharrocks AD, Martins-Green M: MAP kinase phosphorylation-dependent activation of Elk-I leads to activation of the co-activator p300. EMBO J 2003, 22:28I-9I.

26. Kruse J, Gu W: SnapShot: $\mathbf{p 5 3}$ posttranslational modifications. Cell 2008, I33:930-30.el.

27. Wu S, Chiang C: $\mathbf{p 5 3}$ sumoylation: mechanistic insights from reconstitution studies. Epigenetics 2009, 4:445-5I.

28. Vousden $\mathrm{KH}$, Prives $\mathrm{C}$ : Blinded by the Light: The Growing Complexity of p53. Cell 2009, I37:4|3-3I.

29. Wu S, Lee A, Lai H, Zhang H, Chiang C: Phospho switch triggers Brd4 chromatin binding and activator recruitment for genespecific targeting. Mol Cell 2013, 49:843-57.

\section{FlOOOPrime}

RECOMMENDED

30. Bennett RL, Pan Y, Christian J, Hui T, May WS: The RAX/PACTPKR stress response pathway promotes $\mathrm{p} 53$ sumoylation and activation, leading to $\mathbf{G}_{1}$ arrest. Cell Cycle 2012, I I:407-17.

31. Wu S, Chiang C: Crosstalk between sumoylation and acetylation regulates $\mathrm{p} 53$-dependent chromatin transcription and DNA binding. EMBO J 2009, 28:1246-59.

32. Tatham MH, Geoffroy M, Shen L, Plechanovova A, Hattersley N, Jaffray EG, Palvimo JJ, Hay RT: RNF4 is a poly-SUMO-specific E3 ubiquitin ligase required for arsenic-induced PML degradation. Nat Cell Biol 2008, 10:538-46.

\section{FlOOOPrime}

33. Lallemand-Breitenbach V, Jeanne M, Benhenda S, Nasr R, Lei M, Peres L, Zhou J, Zhu J, Raught B, Thé H de: Arsenic degrades PML or PMLRARalpha through a SUMO-triggered RNF4/ubiquitinmediated pathway. Nat Cell Biol 2008, 10:547-55.

\section{FlOOOPrime}

\section{RECOMMENDED}

34. Guo Z, Kanjanapangka J, Liu N, Liu S, Liu C, Wu Z, Wang Y, Loh T, Kowolik C, Jamsen J, Zhou M, Truong K, Chen Y, Zheng L, Shen B: Sequential posttranslational modifications program FEN I degradation during cell-cycle progression. Mol Cell 2012, 47:444-56.

35. La Vega L de, Grishina I, Moreno R, Krüger M, Braun T, Schmitz ML: A redox-regulated SUMO/acetylation switch of HIPK2 controls the survival threshold to oxidative stress. Mol Cell 2012, 46:472-83. 
36. González-Santamaría J, Campagna M, Ortega-Molina A, Marcos-Villar L, La Cruz-Herrera CF de, González D, Gallego P, Lopitz-Otsoa F, Esteban M, Rodríguez MS, Serrano M, Rivas C: Regulation of the tumor suppressor PTEN by SUMO. Cell Death Dis 2012, 3:e393.

37. Bassi C, Ho J, Srikumar T, Dowling RJO, Gorrini C, Miller SJ, Mak TW, Neel BG, Raught B, Stambolic V: Nuclear PTEN controls DNA repair and sensitivity to genotoxic stress. Science 20/3, 341:395-9.

\section{FlOOOPrime} RECOMMENDED

38. Tsao H, Chin L, Garraway LA, Fisher DE: Melanoma: from mutations to medicine. Genes Dev 2012, 26: | |3|-55.

39. Murakami $\mathrm{H}$, Arnheiter $\mathrm{H}$ : Sumoylation modulates transcriptional activity of MITF in a promoter-specific manner. Pigment Cell Res 2005, 18:265-77.

40. Miller AJ, Levy C, Davis IJ, Razin E, Fisher DE: Sumoylation of MITF and its related family members TFE 3 and TFEB. J Biol Chem 2005, 280: 146-55.

41. Yokoyama S, Woods SL, Boyle GM, Aoude LG, MacGregor S, Zismann V, Gartside M, Cust AE, Haq R, Harland M, Taylor JC, Duffy DL, Holohan K, Dutton-Regester K, Palmer JM, Bonazzi V, Stark MS, Symmons J, Law MH, Schmidt C, Lanagan C, O'Connor L, Holland EA, Schmid H, Maskiell JA, Jetann J, Ferguson M, Jenkins MA, Kefford RF, Giles GG, et al.: A novel recurrent mutation in MITF predisposes to familial and sporadic melanoma. Nature 20II, 480:99-103.

\section{FlOOOPrime}

\section{RECOMMENDED}

42. Bertolotto $C$, Lesueur F, Giuliano S, Strub T, de Lichy M, Bille K, Dessen P, d'Hayer B, Mohamdi H, Remenieras A, Maubec E, La de Fouchardière A, Molinié V, Vabres P, Dalle S, Poulalhon N, Martin-Denavit T, Thomas L, Andry-Benzaquen P, Dupin N, Boitier F, Rossi A, Perrot J, Labeille B, Robert C, Escudier B, Caron O, Brugières L, Saule S, Gardie B, et al.: A SUMOylation-defective MITF germline mutation predisposes to melanoma and renal carcinoma. Nature 20II, 480:94-8.

\section{FlOOOPrime
RECOMMENDED}

43. Sturm RA, Fox $C$, McClenahan $P$, Jagirdar $K$, Ibarrola-Villava $M$, Banan P, Abbott NC, Ribas G, Gabrielli B, Duffy DL, Soyer HP: Phenotypic Characterization of Nevus and Tumor Patterns in MITF E3 I8K Mutation Carrier Melanoma Patients. J Invest Dermatol 2013.

\section{FlOOOPrime \\ RECOMMENDED}

44. Ghiorzo P, Pastorino L, Queirolo P, Bruno W, Tibiletti MG, Nasti S, Andreotti V, Paillerets BB, Bianchi Scarrà G: Prevalence of the E3I8K MITF germline mutation in Italian melanoma patients: associations with histological subtypes and family cancer history. Pigment Cell Melanoma Res 2013, 26:259-62.

45. Kessler JD, Kahle KT, Sun T, Meerbrey KL, Schlabach MR, Schmitt EM, Skinner SO, Xu Q, Li MZ, Hartman ZC, Rao M, Yu P, DominguezVidana R, Liang AC, Solimini NL, Bernardi RJ, Yu B, Hsu T, Golding I, Luo J, Osborne CK, Creighton CJ, Hilsenbeck SG, Schiff R, Shaw CA, Elledge SJ, Westbrook TF: A SUMOylation-dependent transcriptional subprogram is required for Myc-driven tumorigenesis. Science 2012, 335:348-53.

\section{FlOOOPrime}

46. Kho C, Lee A, Jeong D, Oh JG, Chaanine AH, Kizana E, Park WJ, Hajiar RJ: SUMOI-dependent modulation of SERCA2a in heart failure. Nature 201I, 477:60I-5.

\section{FlOOOPrime}

47. Ribet D, Hamon M, Gouin E, Nahori M, Impens F, Neyret-Kahn H, Gevaert K, Vandekerckhove J, Dejean A, Cossart P: Listeria monocytogenes impairs SUMOylation for efficient infection. Nature 2010, 464:1192-5.

\section{FlOOOPrime}

48. Everett RD, Boutell C, Hale BG: Interplay between viruses and host sumoylation pathways. Nat Rev Microbiol 20 I3, I I:400- I I.

49. Ahmadian M, Suh JM, Hah N, Liddle C, Atkins AR, Downes M, Evans RM: PPAR $\gamma$ signaling and metabolism: the good, the bad and the future. Nat Med 2013, 19:557-66.

50. Pascual G, Fong AL, Ogawa S, Gamliel A, Li AC, Perissi V, Rose DW, Willson TM, Rosenfeld MG, Glass CK: A SUMOylation-dependent pathway mediates transrepression of inflammatory response genes by PPAR-gamma. Nature 2005, 437:759-63.

\section{FlOOOPrime}

\section{RECOMMENDED}

5I. Yamashita D, Yamaguchi T, Shimizu M, Nakata N, Hirose F, Osumi T: The transactivating function of peroxisome proliferatoractivated receptor gamma is negatively regulated by SUMO conjugation in the amino-terminal domain. Genes Cells 2004, 9:1017-29.

52. Floyd ZE, Stephens JM: Control of peroxisome proliferatoractivated receptor gamma2 stability and activity by SUMOylation. Obes Res 2004, 12:921-8.

53. Ohshima T, Koga H, Shimotohno K: Transcriptional activity of peroxisome proliferator-activated receptor gamma is modulated by SUMO-I modification. J Biol Chem 2004, 279: 2955 I-7.

54. Dutchak PA, Katafuchi T, Bookout AL, Choi JH, Yu RT, Mangelsdorf DJ Kliewer SA: Fibroblast growth factor-2I regulates PPAR activity and the antidiabetic actions of thiazolidinediones. Cell 20I2, I 48:556-67.

\section{FlOOOPrime
RECOMMENDED}

55. Nacerddine K, Lehembre F, Bhaumik M, Artus J, Cohen-Tannoudji M, Babinet C, Pandolfi PP, Dejean A: The SUMO pathway is essential for nuclear integrity and chromosome segregation in mice. Dev Cell 2005, 9:769-79.

\section{FlOOOPrime}

\section{RECOMMENDED}

56. Nowak M, Hammerschmidt M: Ubc9 regulates mitosis and cell survival during zebrafish development. Mol Biol Cell 2006, 17:5324-36.

57. Demarque MD, Nacerddine K, Neyret-Kahn H, Andrieux A, Danenberg E, Jouvion G, Bomme P, Hamard G, Romagnolo B, Terris B, Cumano A, Barker N, Clevers H, Dejean A: Sumoylation by Ubc9 regulates the stem cell compartment and structure and function of the intestinal epithelium in mice. Gastroenterology 20II, I40:286-96.

\section{FlOOOPrime}

\section{RECOMMENDED}

58. Takahashi K, Yamanaka S: Induction of pluripotent stem cells from mouse embryonic and adult fibroblast cultures by defined factors. Cell 2006, I 26:663-76.

\section{FlOOOPrime RECOMMENDED}

59. Kawai-Kowase K, Ohshima T, Matsui H, Tanaka T, Shimizu T, Iso T, Arai M, Owens GK, Kurabayashi M: PIASI mediates TGFbetainduced SM alpha-actin gene expression through inhibition of KLF4 function-expression by protein sumoylation. Arterioscler Thromb Vasc Biol 2009, 29:99-106.

60. Tsuruzoe $S$, Ishihara $K$, Uchimura $Y$, Watanabe $S$, Sekita $Y$, Aoto $T$, Saitoh H, Yuasa Y, Niwa H, Kawasuji M, Baba H, Nakao M: Inhibition of DNA binding of Sox 2 by the SUMO conjugation. Biochem Biophys Res Commun 2006, 351:920-6. 
6I. Wei F, Schöler HR, Atchison ML: Sumoylation of Oct4 enhances its stability, DNA binding, and transactivation. J Biol Chem 2007, 282:2I55I-60.

62. Tolkunova E, Malashicheva A, Parfenov VN, Sustmann C, Grosschedl R, Tomilin A: PIAS proteins as repressors of Oct4 function. J Mol Biol 2007, 374: I200-12.

63. Tahmasebi S, Ghorbani M, Savage P, Yan K, Gocevski G, Xiao L, You L, Yang $X$ : Sumoylation of Krüppel-like factor 4 inhibits pluripotency induction but promotes adipocyte differentiation. J Biol Chem 2013, 288: 1279|-804.

64. Heng JD, Feng B, Han J, Jiang J, Kraus $P, N g$ J, Orlov $Y L$, Huss $M$, Yang L, Lufkin T, Lim B, Ng H: The nuclear receptor Nr5a2 can replace Oct4 in the reprogramming of murine somatic cells to pluripotent cells. Cell Stem Cell 2010, 6:167-74.

FlOOOPrime
RECOMMENDED

65. Feng B, Jiang J, Kraus P, Ng J, Heng JD, Chan Y, Yaw L, Zhang W, Loh Y, Han J, Vega VB, Cacheux-Rataboul V, Lim B, Lufkin T, Ng H: Reprogramming of fibroblasts into induced pluripotent stem cells with orphan nuclear receptor Esrrb. Nat Cell Biol 2009, I I:197-203.

FlOOOPrime

RECOMMENDED 